\title{
Research Article \\ Effect of Heating at Oven-Dry State on Steam Treated Bamboo Powder Thermal Fluidity
}

\author{
S. Kajikawa and T. Iizuka \\ Department of Mechanical and System Engineering, Kyoto Institute of Technology, Matsugasakigoshokaido-cho, \\ Sakyo-ku, Kyoto 606-8585, Japan \\ Correspondence should be addressed to S. Kajikawa; d3821003@edu.kit.ac.jp
}

Received 20 February 2015; Revised 8 June 2015; Accepted 30 July 2015

Academic Editor: Jiang Jianchun

Copyright (C) 2015 S. Kajikawa and T. Iizuka. This is an open access article distributed under the Creative Commons Attribution License, which permits unrestricted use, distribution, and reproduction in any medium, provided the original work is properly cited.

\begin{abstract}
In hot molding processes of woody material, it is important to understand the effect of oven-dry heating on the property of woody biomass material, such as thermal fluidity. In this study, thermal flow tests of untreated and steam treated bamboo powder were conducted to investigate the effects of heating at an oven-dry state on thermal fluidity. The test temperature was set to $200^{\circ} \mathrm{C}$. Before the thermal flow test, powder was dry-heated in a capillary rheometer at $200^{\circ} \mathrm{C}$ with a variable heating time. Thermogravimetry was conducted to understand the thermal changes of the powder during an increasing temperature and constant temperature. Fluidity of untreated powder was improved with a short dry-heating but decreased with a long dry-heating. In contrast, steam treated powder fluidity was high compared to untreated one, but its fluidity did not improve from dry-heating. From these thermogravimetry results, the chemical changes associated with component volatilization relate with the thermal fluidity. Therefore, the decrease in fluidity from dry-heating occurred because fluidity related components escape from the powder through volatilization.
\end{abstract}

\section{Introduction}

Effective use of woody biomass resources is environmentally friendly because woody biomass resources are carbon neutral and sustainable. However, applications for woody biomass materials are limited because of some inherent practicality issues. One issue is material workability. Woody biomass is generally processed through machining, bending, or compacting. However, processing complex shapes is difficult, and some problems, such as limited extraction rates and productivity, exist with these methods.

In order to resolve these problems, various research studies on woody material processing methods have been conducted. For example, wood plastic composites (WPC), which are made by mixing woody materials and plastics, can be processed with general plastic processing methods such as extrusion or injection molding [1-3]. Methods where petroleum-derived materials were not used have also been developed. It was reported that molding of only woody materials containing water was possible at $170-180^{\circ} \mathrm{C}$ because woody materials have thermal fluidity and self-adhesiveness due to the hydrolysis of the material's chemical components [4-6]. In addition, it was reported that thermal fluidity and self-adhesiveness could be improved by steam treatment [710]. It is considered that these woody properties changes occur due to water soluble components increasing with the hydrolysis of the materials chemical components, such as hemicellulose, during steam treatment [11-13]. Injection molding is possible without water by using steam treated woody powder, and strength of injection molded product came up to that of polypropylene $[14,15]$. This way, thermal fluidity of woody material can be controlled for the improvement of moldability by heating at the wet state, such as steaming.

Woody material properties are affected by heating not only during the wet state, such as steaming, but also during the dry state. For example, research about woody material dry-heating has shown that dynamic viscoelastic properties of dry wood change in relation to its heating temperature or time [16]. In addition, thermal changes to the physical 


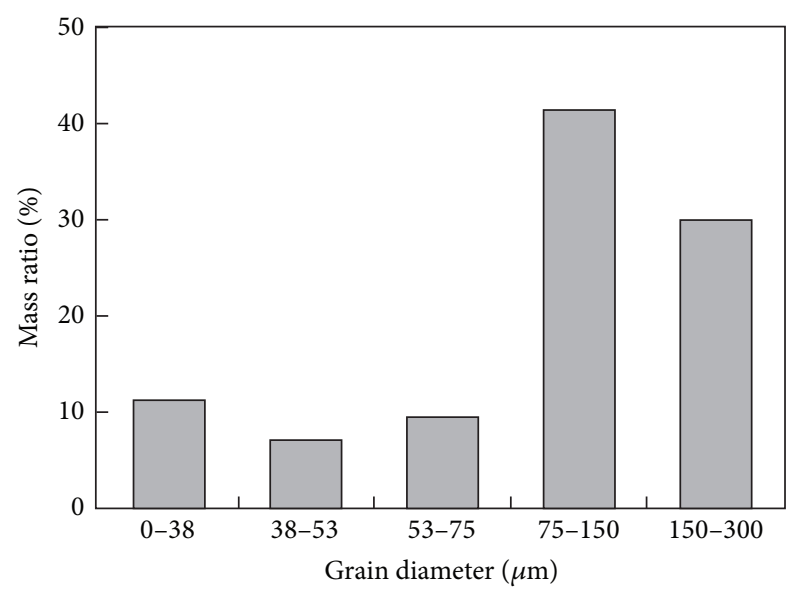

FIgURE 1: Particle size distribution of bamboo powder.

property, such as thermal softening, in the dry state are different from those in the wet state $[10,17]$. Accordingly, it is possible that the thermal flowability of woody material is affected by dry-heating. However, the effect of dry-heating on the thermal fluidity of woody material is not fully understood. For actual hot molding processes for woody material, it is important to understand these effects.

In this study, a thermal flow test for woody materials dry-heated for different treating time was conducted using a capillary rheometer. Bamboo powder, which was untreated or steam treated, was studied because an effective use of the timber from bamboo thinning is desired in Japan [18]. In addition, it was reported that bamboo fluidity is high compared to other woody materials [19]. This reason is the fact that hemicellulose of bamboo is mainly xylan [20] and xylan having acetyl group produces acid which catalyzes hydrosis [12]. Thermogravimetry for bamboo powder was conducted in order to investigate the thermal change effects during dry-heating. From these results, the relationship between thermal fluidity and chemical changes in bamboo powder during dry-heating is discussed.

\section{Materials and Methods}

2.1. Preparation of the Materials. Moso bamboo powder was used. To obtain the powder, a stem was shaved and shavings were then milled in a pin mill. The powder passed through a $\phi 300 \mu \mathrm{m}$ screen during the milling stage. Figure 1 shows the powder particle size distribution, which was predominately in the range of $75-300 \mu \mathrm{m}$.

Figure 2 shows a schematic diagram of the bamboo powder steam treatment. The powder was treated with saturated water vapor at a high temperature by heating a small pressure vessel containing the powder and water. First, the vessel was heated to a target temperature of $T_{s}\left({ }^{\circ} \mathrm{C}\right)$. Next, the temperature $T_{s}$ was held for a predefined time $t_{s}(\mathrm{~min})$. The vessel was then cooled to $100^{\circ} \mathrm{C}$. The powder was tapped off from the vessel and air-dried at room temperature. Air-dried powder was dried additionally in an oven at constant $105^{\circ} \mathrm{C}$ to achieve an oven-dry state before the thermal flow test.

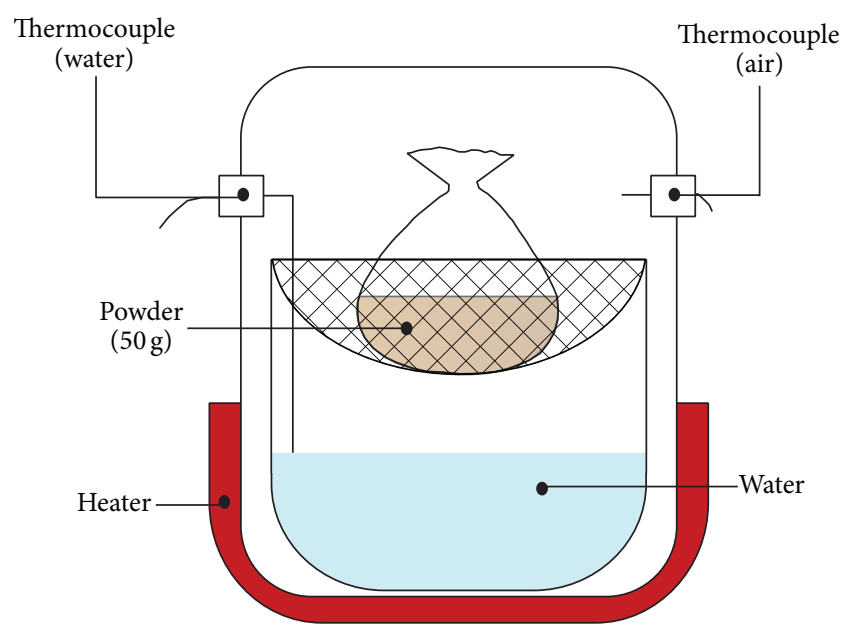

FIGURE 2: Schematic diagram of steam treatment.

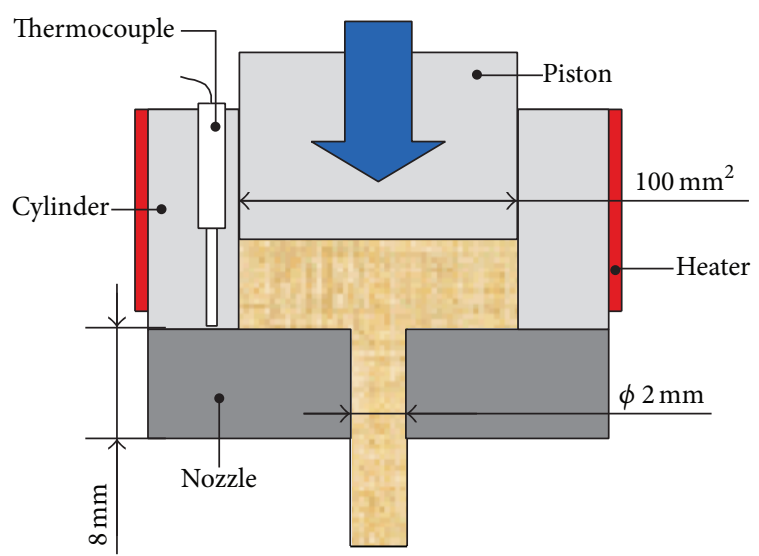

FIGURE 3: Schematic diagram of the capillary rheometer.

2.2. Thermal Flow Test. A capillary rheometer (CFT-500D, Shimadzu) was used to dry-heat the powder and for the thermal flow test. Figure 3 shows a schematic diagram of the capillary rheometer. First, the capillary rheometer was heated to a test temperature of $200^{\circ} \mathrm{C}$ because bamboo fluidity is activated at $200^{\circ} \mathrm{C}$ [4]. Powder with a mass of $1.5 \mathrm{~g}$ was placed in the cylinder followed by a piston. The powder was then heated for a predefined time $t_{h}(\mathrm{~min})$ in the cylinder. The piston was compressed at $49 \mathrm{MPa}$ and material was extruded from the nozzle. The piston movement during the material extrusion was evaluated.

2.3. Thermogravimetry. Thermogravimetry was conducted with a thermogravimetry/differential thermal analyzer (TG/DTA 6200, Seiko Instruments Inc.). The air-dried bamboo powder was placed in an aluminum pan, and an empty aluminum pan was used as a reference. Figure 4 shows the temperature program. First, drying at $105^{\circ} \mathrm{C}$ for $30 \mathrm{~min}$ with a dry nitrogen gas purge was performed to ensure that moisture state of the powder was oven-dry in the device. The temperature was raised to $200^{\circ} \mathrm{C}$ at a constant rate of $10^{\circ} \mathrm{C} / \mathrm{min}$ and held for $60 \mathrm{~min}$. Changes in mass loss rate 


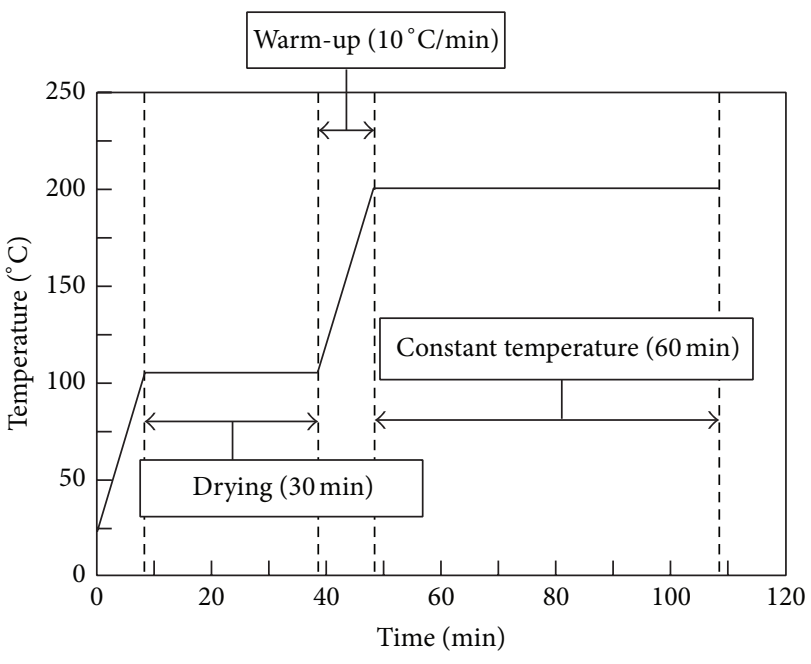

Figure 4: Thermogravimetry temperature schedule.

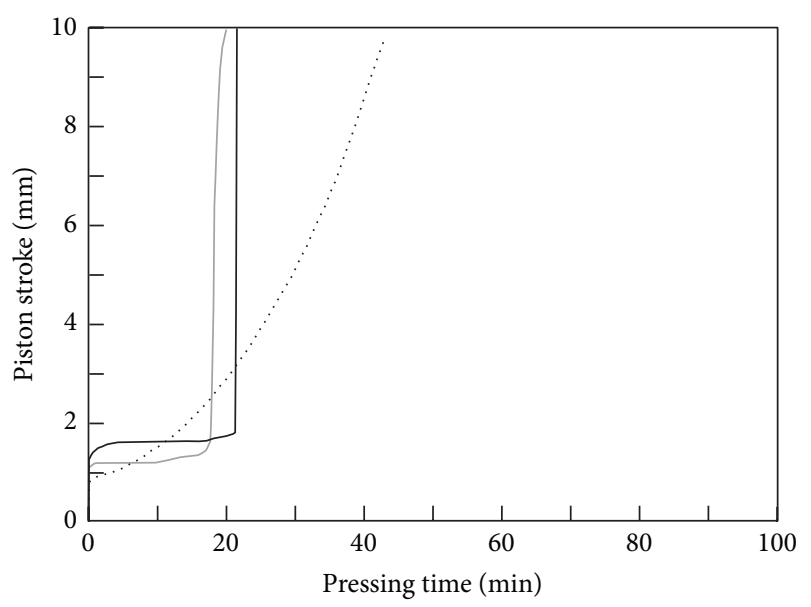

Steam treatment temperature $T_{\mathcal{s}}\left({ }^{\circ} \mathrm{C}\right)$

— Untreated

180

…. 200

FIGURE 5: Effect of steam treatment temperature $T_{s}$ on the thermal flow curve. $\left(t_{s}=20 \mathrm{~min}\right.$ and $\left.t_{h}=5 \mathrm{~min}\right)$.

$(\% / \mathrm{min})$ based on the oven-dry mass were evaluated during the warm-up period and the constant temperature period.

\section{Results and Discussion}

3.1. Thermal Flow Curve of Untreated and Steam Treated Bamboo Powder. Flow behavior of untreated and steam treated bamboo powder was investigated. Figure 5 shows the relationship between press time and piston stroke motion when the steam temperature $T_{s}$ was changed. The steam treatment time $t_{s}$ was set at $20 \mathrm{~min}$ and the heating time $t_{h}$ was set at $5 \mathrm{~min}$. It was considered that the powder temperature achieved $200^{\circ} \mathrm{C}$ with a $5 \mathrm{~min}$ heating interval because we confirmed that the temperature of the powder near the surface was $200^{\circ} \mathrm{C}$ after 3-4 min.

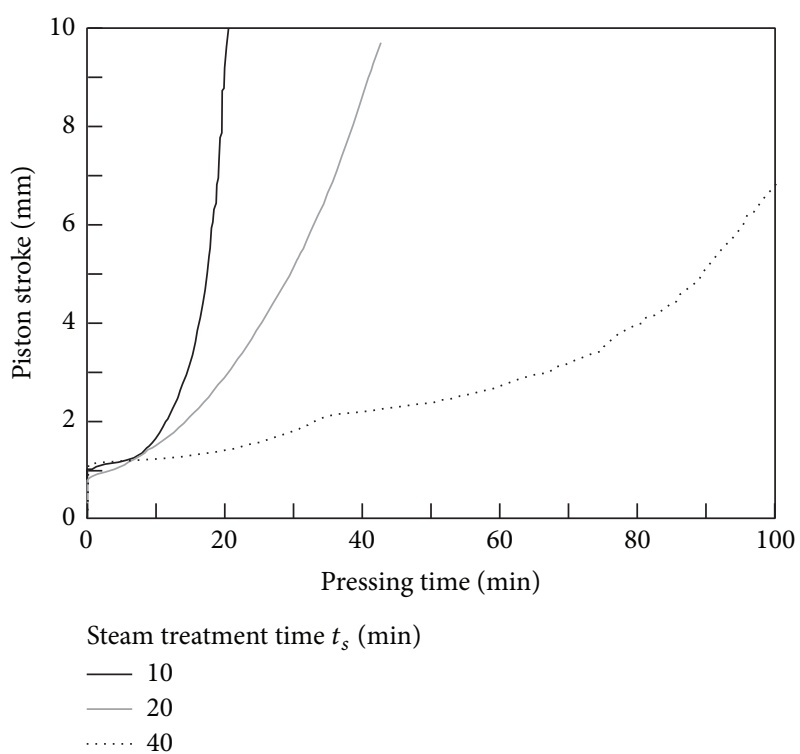

FIGURE 6: Effect of steam treatment time $t_{h}$ on the thermal flow curve. $\left(T_{s}=200^{\circ} \mathrm{C}\right.$ and $\left.t_{h}=5 \mathrm{~min}\right)$.

As shown in Figure 5, the untreated and $T_{s}=180^{\circ} \mathrm{C}$ powder did not flow immediately but rapidly increased in rate when the pressing time reached about $20 \mathrm{~min}$. It was determined that the fluidity was provided by thermal decomposition from heat caused by the piston pressure. Gas is exhausted during thermal decomposition of wood biomass material [21], but it is difficult for the gas to escape from the cylinder until the flow starts because the powder is in a high pressure state. Therefore, the material flowed drastically when the gas could escape once the flow started. In contrast, the $T_{s}=200^{\circ} \mathrm{C}$ powder flowed immediately once pressed but at a slower flow rate. Accordingly, it was determined that powder fluidity is simple to increase because the powder has flow components produced by the preliminary steam treatment. In addition, a rapid flow rate increase could not have occurred because the gas was able to escape gradually with material flow.

Figure 6 shows the relationship between pressing time and piston stroke motion when the steaming time $t_{s}$ was changed. In this experimental series, $T_{s}$ was set at $200^{\circ} \mathrm{C}$ because flow behavior changed largely with a steam treatment of $200^{\circ} \mathrm{C}$, as shown in Figure 5. The flow rate slows with an increase in $t_{s}$. This result suggests that a long steam treatment has a negative effect on thermal fluidity.

3.2. Effects of Dry-Heating Time on the Bamboo Powder Thermal Flow Curve. Figure 7 shows the thermal flow curve changes for each powder by dry-heating time $t_{h}$. The range of $t_{h}$ tested was from 1 to 20 min. For untreated powder, flow started sooner when $t_{h}$ increased from 1 to $5 \mathrm{~min}$, but the start was delayed with a further increase in $t_{h}$ over $5 \mathrm{~min}$ as shown in Figure 7(a). In contrast, for steam treated powder, the flow began soonest when $t_{h}$ was $1 \mathrm{~min}$, while the flow start was delayed with an increase in $t_{h}$ as shown in Figures 7(b)-7(e). In particular, powder steam treated at $200^{\circ} \mathrm{C}$ for 10 and $20 \mathrm{~min}$ had no flow when $t_{h}$ was $20 \mathrm{~min}$ and that for $40 \mathrm{~min}$ had no 

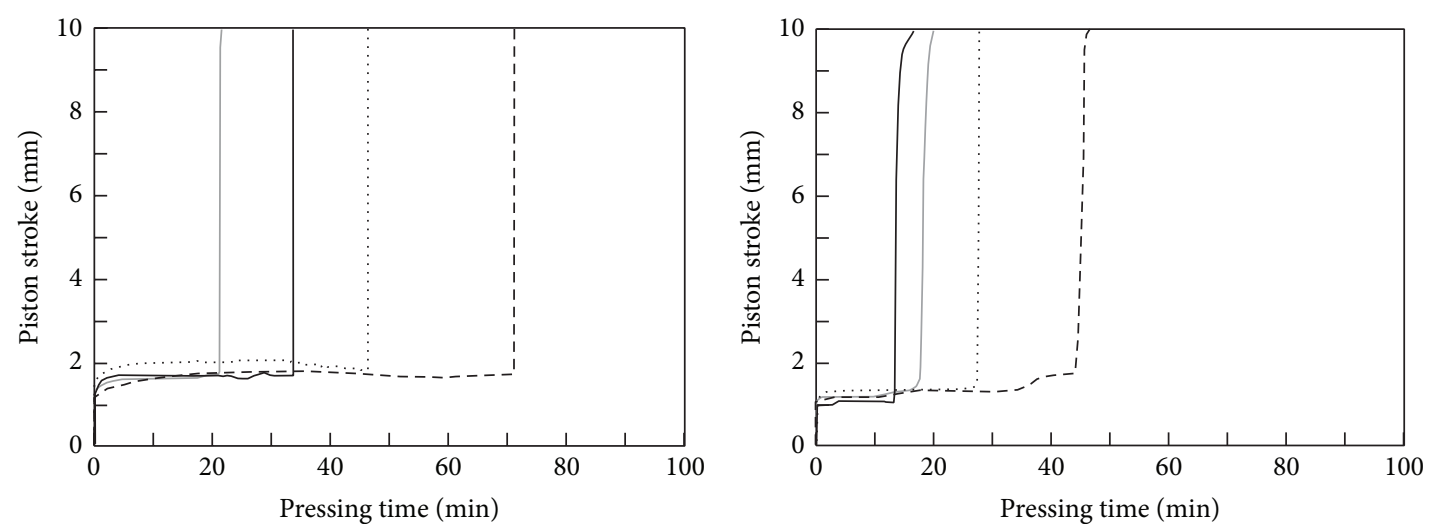

Dry-heating time $t_{h}(\mathrm{~min})$

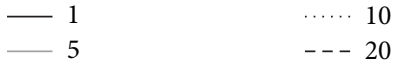

(a) Untreated

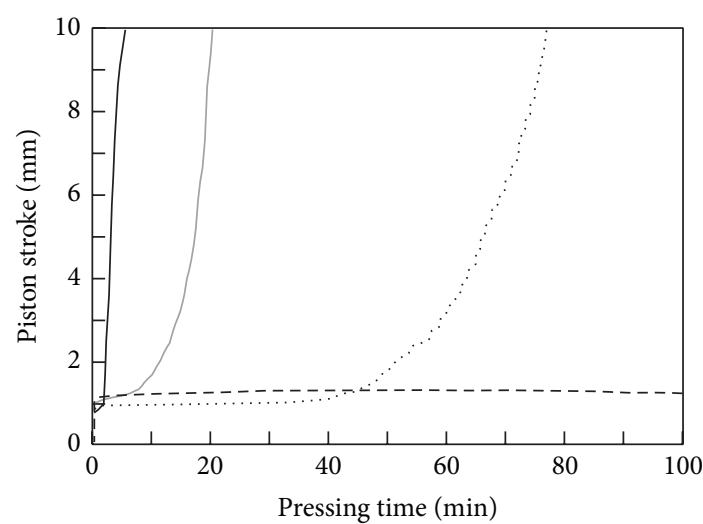

Dry-heating time $t_{h}(\mathrm{~min})$

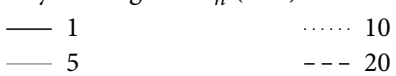

(c) $T_{s}=200^{\circ} \mathrm{C}, t_{s}=10 \mathrm{~min}$
Dry-heating time $t_{h}(\min )$

$\begin{array}{rll}1 & \cdots & 10 \\ 5 & ---20\end{array}$

(b) $T_{s}=180^{\circ} \mathrm{C}, t_{s}=20 \mathrm{~min}$

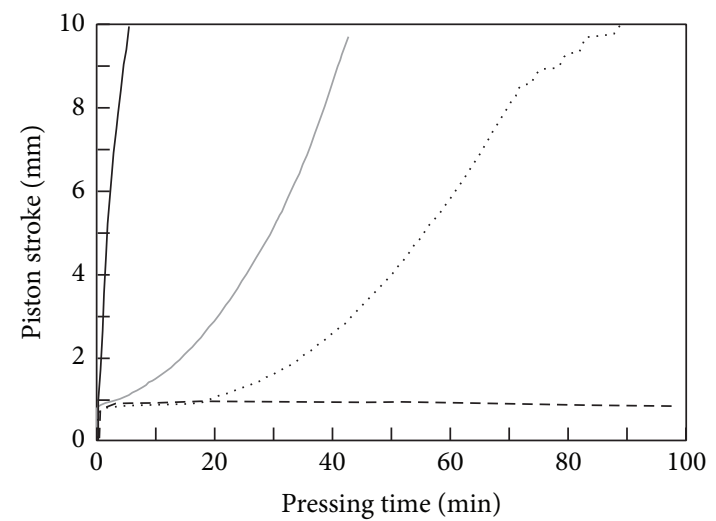

Dry-heating time $t_{h}(\mathrm{~min})$

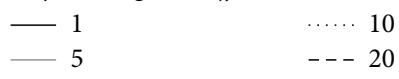

(d) $T_{s}=200^{\circ} \mathrm{C}, t_{s}=20 \mathrm{~min}$

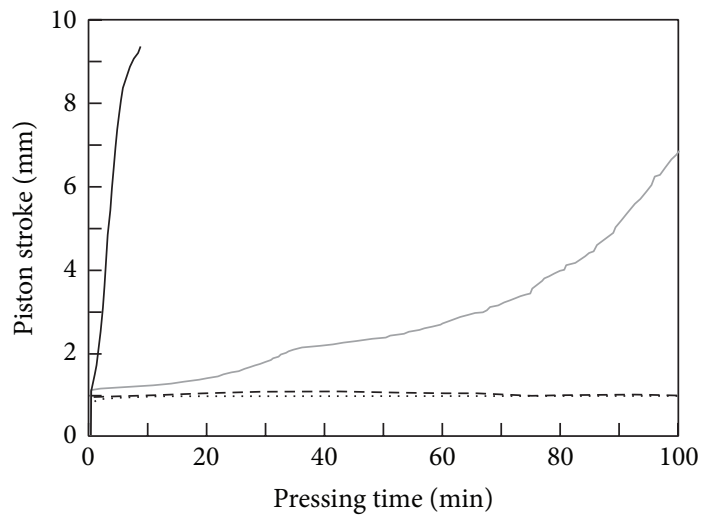

Dry-heating time $t_{h}(\min )$

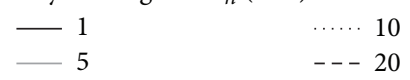

(e) $T_{s}=200^{\circ} \mathrm{C}, t_{s}=40 \mathrm{~min}$

FIgURE 7: Effect of dry-heating time $t_{h}$ on the thermal flow curve when the steam treatment temperature is changed. 


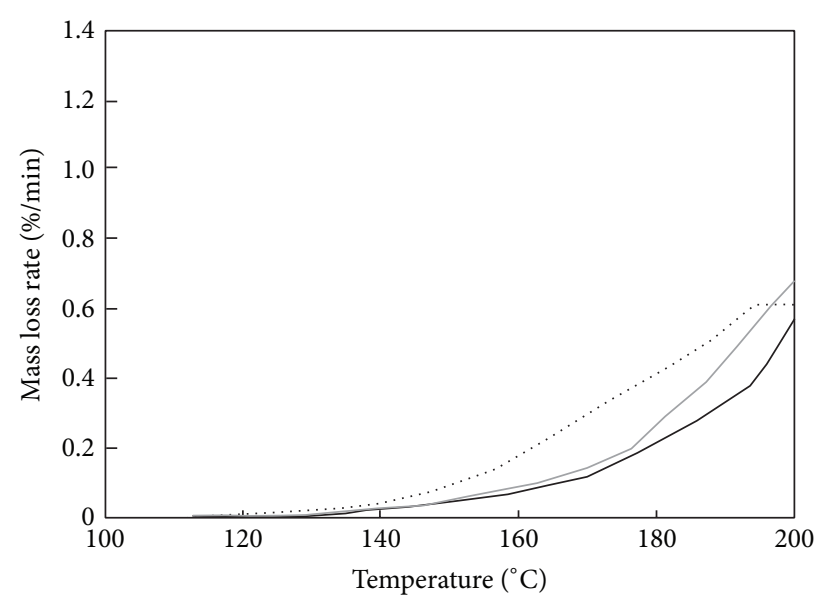

Steam treatment temperature $T_{s}\left({ }^{\circ} \mathrm{C}\right)$

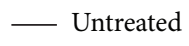

180

…. 200

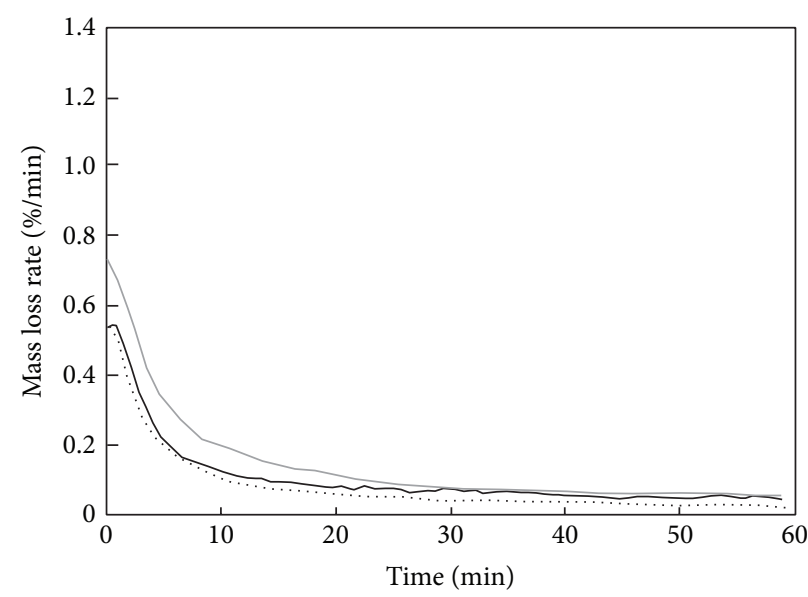

Steam treatment temperature $T_{s}\left({ }^{\circ} \mathrm{C}\right)$

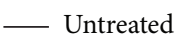

180

..... 200

(a) Warm-up period

(b) Constant temperature period

FIGURE 8: Mass change rates of bamboo powder untreated and steam treated with a variable steam treatment temperature $T_{s}$. $\left(t_{s}=20\right.$ min $)$.

flow when $t_{h}$ was over $10 \mathrm{~min}$. The powder temperature did not reach $200^{\circ} \mathrm{C}$ yet when $t_{h}$ was only $1 \mathrm{~min}$. Accordingly, powder fluidity at $T_{s}=200^{\circ} \mathrm{C}$, which flowed immediately for $t_{h}=1 \mathrm{~min}$, could have become activated at a temperature under $200^{\circ} \mathrm{C}$. These results suggest that untreated powder can be activated by heating under ordinary pressure for a short time. For steam treated powder, it was confirmed that dryheating has a negative effect on thermal fluidity regardless of steam treatment temperature or time.

\subsection{Bamboo Powder Mass Loss during Warm-Up and Constant} Temperature Periods. Figure 8 shows the mass loss rate for bamboo powder during the temperature increase to $200^{\circ} \mathrm{C}$ and when being held constant at $200^{\circ} \mathrm{C}$ for a variable steam treatment temperature $T_{s}$. The steam treatment time $t_{s}$ of steam treated powder was $20 \mathrm{~min}$. The mass loss rate shows the chemical change intensity because component volatilization occurs from woody material thermal decomposition [21]. As shown in Figure 8(a), mass loss starts when the temperature reaches about $140^{\circ} \mathrm{C}$. The amount of mass lost for steam treated powder was higher than that of untreated powder. In particular, the mass loss rate for $T_{s}=180^{\circ} \mathrm{C}$ surpassed that of untreated powder when the temperature reached about $160^{\circ} \mathrm{C}$, where it continued to increase until $200^{\circ} \mathrm{C}$. This result suggests that chemical changes in powder are activated by a $180^{\circ} \mathrm{C}$ steam treatment. For $T_{s}=200^{\circ} \mathrm{C}$, the mass loss rate surpassed the untreated powder at about $145^{\circ} \mathrm{C}$, and it continued to increase until $190-195^{\circ} \mathrm{C}$. This suggests that the chemical changes become active at a lower temperature and the intensity relaxes at $190-200^{\circ} \mathrm{C}$. With constant temperature, the mass loss rate of each powder decreases with time and ceases after about $30 \mathrm{~min}$ as shown in Figure 8(b). The mass loss rate for $T_{s}=180^{\circ} \mathrm{C}$ powder is comparatively high until $30 \mathrm{~min}$. This result indicates that chemical changes continued for $30 \mathrm{~min}$ after increasing the temperature to $200^{\circ} \mathrm{C}$, and $T_{s}=180^{\circ} \mathrm{C}$ powder was the most active at constant temperature.

Figure 9 shows the bamboo powder mass loss rate for $T_{s}=$ $200^{\circ} \mathrm{C}$ during the temperature increase to $200^{\circ} \mathrm{C}$ and when being held constant at $200^{\circ} \mathrm{C}$ for a variable steam treatment time $t_{s}$. In the warm-up period, as shown in Figure 9(a), the amount of mass lost decreases with increasing $t_{s}$. The mass loss rates for $t_{s}=10$ and $20 \mathrm{~min}$ become constant at $190-195^{\circ} \mathrm{C}$, while $t_{s}=40 \mathrm{~min}$ becomes constant at about $185^{\circ} \mathrm{C}$. This result suggests that the chemical change intensity decreases with an increase in $t_{s}$. For constant steam treatment temperature, as shown in Figure 9(b), the mass loss rate for each powder decreases and becomes constant at $30 \mathrm{~min}$.

It was reported that water-soluble components are produced from hemicellulose by steam treatment and some of these components change to volatile components, such as furfural, from high temperature at a prolonged exposure time [11]. Thus, an increase in mass loss from steam treatment could have been due to an increase in volatile water-soluble components. For long $t_{s}$, it is possible that powder loses its water-soluble components through dissolving with water or volatilization during steam treatment. For this reason, it was determined that the amount of mass loss decreases with an increase in $t_{s}$.

Relationship between thermal fluidity and mass loss during warm-up and constant temperature periods is discussed. As shown in Figures 5 and $8, T_{s}=200^{\circ} \mathrm{C}$ powder flow starts early compared to the other steam treatment temperatures and mass change begins at a lower rheometer temperature. It was reported that chemical changes associated with component volatilization relate with woody material thermal fluidity $[13,19]$. It was determined that $T_{s}=200^{\circ} \mathrm{C}$ powder fluidity was adequately activated during the 5 min dry-heating. For 


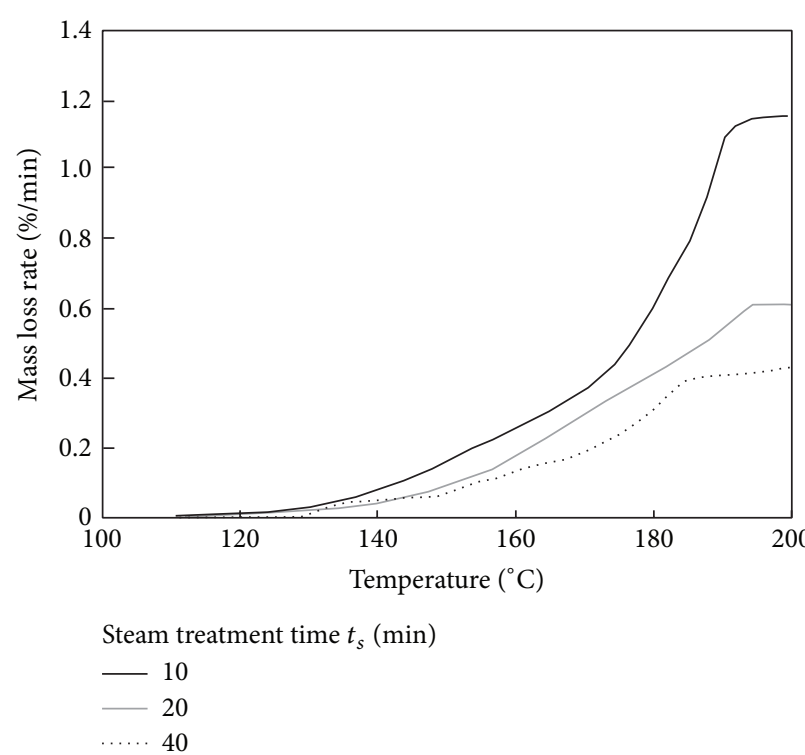

(a) Warm-up period

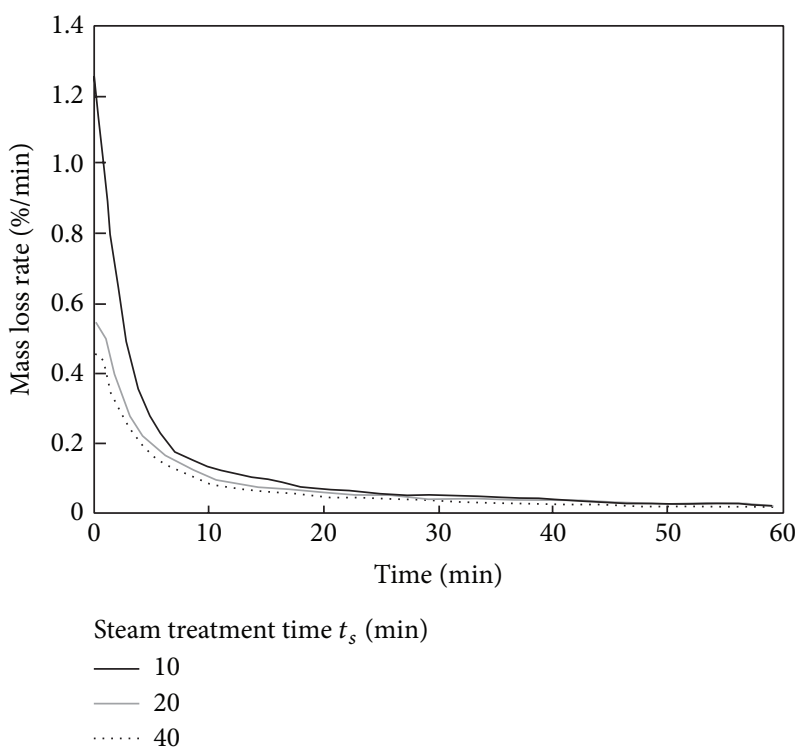

(b) Constant temperature period

Figure 9: Mass loss rate for steam treated bamboo powder with a variable steam treatment time $t_{s} .\left(T_{s}=200^{\circ} \mathrm{C}\right)$.

untreated and steam treated powder at $180^{\circ} \mathrm{C}$, fluidity was not adequately activated after $5 \mathrm{~min}$ of dry-heating. Thus, flow started after about $20 \mathrm{~min}$ of pressing time and $T_{s}=$ $180^{\circ} \mathrm{C}$ powder flow start began earlier than the untreated powder because chemical changes at $T_{s}=180^{\circ} \mathrm{C}$ were more active with a constant rheometer temperature. The thermal fluidity changes from $t_{s}$, as shown in Figure 6, were also caused by the intensity differences in the chemical changes associated with the component volatilization. $T_{s}=200^{\circ} \mathrm{C}$ powder flow started immediately after pressing because the chemical changes caused by the 5 min dry-heating activated the fluidity, but the chemical change intensity decreases with an increase in $t_{s}$ as shown in Figure 9(a). Therefore, the flow rate decreases with an increase in $t_{s}$.

Next, we discuss the effect of dry-heating time on thermal fluidity in an oven-dry state and the chemical changes during dry-heating. For untreated powder as shown in Figure 7(a), it was determined that the flow started early when $t_{h}$ increased from 1 to $5 \mathrm{~min}$ because the fluidity was activated by a 5 min dry-heating. However, the flow started later with an increase in $t_{h}$ from 5 to $20 \mathrm{~min}$. It is possible that this is because of component volatilization. It was considered that volatile components have a large effect on thermal fluidity, but the volatile components escape from the powder during dry-heating because dry-heating was conducted under atmospheric pressure. As shown in Figure 8(b), it can be seen that volatilization occurred for $30 \mathrm{~min}$ in each powder. Accordingly, the powder fluidity decreases with an increase in $t_{h}$ because of volatile components escaping from the powder during dry-heating. By contrast, component volatilization could have been inhibited during pressing due to the powder's high pressure state. Thus, fluidity was activated through pressing and heating from occurring chemical changes, while the volatile components remain in the powder.
For steam treated powder, the flow showed a tendency to start later at a slower rate as $t_{h}$ changed from 1 to $20 \mathrm{~min}$ as shown in Figures 7(b)-7(e). The volatilization amount was larger than that of untreated powder until the temperature reached $200^{\circ} \mathrm{C}$, as shown in Figures 8(a) and 9(a). Therefore, the fluidity of steam treated powder was activated with ease until the temperature reached $200^{\circ} \mathrm{C}$, but the negative effect volatilization has on fluidity was greater than the heating effect for fluidity activation when the temperature reached $200^{\circ} \mathrm{C}$.

\section{Conclusions}

In this study, thermal flow tests of untreated and steam treated bamboo powder were performed using a capillary rheometer to investigate the effect of heating at an oven-dry state on thermal fluidity. The test temperature and dry heating temperature were set at $200^{\circ} \mathrm{C}$. Untreated and steam treated bamboo powder at $180^{\circ} \mathrm{C}$ started to flow several minutes after the start of pressing. Steam treated powder at $200^{\circ} \mathrm{C}$ flowed immediately after pressing. When the powder dry-heating time increased in an oven-dry state before pressing, the untreated powder flow began earlier with an increase in dryheating time from 1 to $5 \mathrm{~min}$ but started later with an increase in dry-heating time from 5 to $20 \mathrm{~min}$. The flow of the steam treated powder started later with an increase in dry-heating time from 1 to $20 \mathrm{~min}$. From the thermogravimetry results during the increasing and constant temperature periods, it was confirmed that chemical changes associated with component volatilization relate with thermal fluidity. For untreated powder, fluidity is improved from chemical changes during a short dry-heating, but fluidity decreases because the powder loses its fluidity related components from volatilization with a long dry-heating. For steam treated powder, fluidity was 
high when the dry-heating was short because of the chemical change intensity associated with volatilization. It was easy to slow fluidity with dry-heating because the powder readily loses its fluidity related components due to the large amount of volatilization.

\section{Conflict of Interests}

The authors declare that there is no conflict of interests regarding the publication of this paper.

\section{Acknowledgment}

This work was supported by JSPS KAKENHI (Grant nos. 24360309 and 26-9571).

\section{References}

[1] S. Migneault, A. Koubaa, F. Erchiqui et al., "Effect of fiber length on processing and properties of extruded wood-fiber/HDPE composites," Journal of Applied Polymer Science, vol. 110, no. 2, pp. 1085-1092, 2008.

[2] M. Seki, T. Miki, S. Tanaka, I. Shigematsu, and K. Kanayama, "Effect of thermoplastic binder on flow deformation behavior of wood," Procedia Engineering, vol. 81, pp. 855-860, 2014.

[3] N. M. Stark, L. M. Matuana, and C. M. Clemons, "Effect of processing method on surface and weathering characteristics of wood-flour/HDPE composites," Journal of Applied Polymer Science, vol. 93, no. 3, pp. 1021-1030, 2004.

[4] O. Yamashita, Yokochi, H. Imanishi, and K. Kanayama, "Transfer molding of bamboo," Journal of Materials Processing Technology, vol. 192-193, pp. 259-264, 2007.

[5] S. Ellis and L. Paszner, "Activated self-bonding of wood and agricultural residues," Holzforschung, vol. 48, pp. 82-90, 1994.

[6] O. V. Startsev, B. N. Salin, Y. G. Skuridin, R. M. Utemesov, and A. D. Nasonov, "Physical properties and molecular mobility of the new wood composite plastic 'thermobalite," Wood Science and Technology, vol. 33, no. 1, pp. 73-83, 1999.

[7] I. Takahashi, Y. Takasu, T. Sugimoto, Y. Kikata, and Y. Sasaki, "Thermoplastic flow behavior of steamed wood flour under heat and compression," Wood Science and Technology, vol. 44, no. 4, pp. 607-619, 2010.

[8] N. Laemsak and M. Okuma, "Development of boards made from oil palm frond II: properties of binderless boards from steam-exploded fibers of oil palm frond," Journal of Wood Science, vol. 46, no. 4, pp. 322-326, 2000.

[9] I. Takahashi, T. Sugimoto, Y. Takasu, M. Yamasaki, Y. Sasaki, and Y. Kikata, "Effect of wood species on thermal flow behavior and physical properties of thermoplastic moldings," Wood Science and Technology, vol. 46, no. 1-3, pp. 419-429, 2012.

[10] W. E. Hillis and A. N. Rozsa, "High temperature and chemical effects on wood stability," Wood Science and Technology, vol. 19, no. 1, pp. 57-66, 1985.

[11] M. Tanahashi, "Characterization and degradation mechanisms of wood components by steam explosion and utilization of exploded wood," Wood Research, no. 77, pp. 49-117, 1990.

[12] B. F. Tjeerdsma and H. Militz, "Chemical changes in hydrothermal treated wood: FTIR analysis of combined hydrothermal and dry heat-treated wood," Holz Als Roh- und Werkstoff, vol. 63, no. 2, pp. 102-111, 2005.
[13] S. Kajikawa and T. Iizuka, "Effect of water-soluble components mass on the fluidity of the steam-treated bamboo powder caused by heating and compression," Journal of the Society of Materials Science, Japan, vol. 64, no. 5, pp. 381-386, 2015 (Japanese).

[14] S. Kajikawa and T. Iizuka, "Injection molding using only $200^{\circ} \mathrm{C}$ steamed bamboo powder by controlling metal mold temperature," Procedia Engineering, vol. 81, pp. 1186-1191, 2014.

[15] S. Kajikawa and T. Iizuka, "Effect of molding temperature on fluidity and injection moldability of oven-dry steam-treated bamboo powder," Journal of Materials Processing Technology, vol. 225, pp. 433-438, 2015.

[16] K. Kojiro, Y. Furuta, and Y. Ishimaru, "Influence of heating history on dynamic viscoelastic properties and dimensions of dry wood," Journal of Wood Science, vol. 54, no. 3, pp. 196-201, 2008.

[17] D. A. I. Goring, “Thermal softening of lignin, hemicellulose and cellulose," Pulp Paper Magazine of Canada, vol. 64, no. 12, pp. T517-T527, 1963.

[18] H. Hiura, T. Arikawa, and D. D. Bahadur, "Risk of sediment related disasters due to the abandoned expanding bamboo stands at the foot of slopes surrounding city area," Journal of the Japan Landslide Society, vol. 41, no. 4, pp. 323-334, 2004 (Japanese).

[19] E. Udaka, T. Miki, H. Sugimoto, and K. Kanayama, "Ryudou seikei ni okeru baiomasu no ryudou mekanizumu no kaimei," Kagawa Prefectural Industrial Technology Research Center Kenkyu Houkoku, vol. 9, pp. 11-14, 2009 (Japanese).

[20] W. Liese, "Research on bamboo," Wood Science and Technology, vol. 21, no. 3, pp. 189-209, 1987.

[21] W. Jim, K. Singh, and J. Zondlo, "Pyrolysis kinetics of physical components of wood-polymers using isoconversion method," Agriculture, vol. 3, pp. 12-32, 2013. 

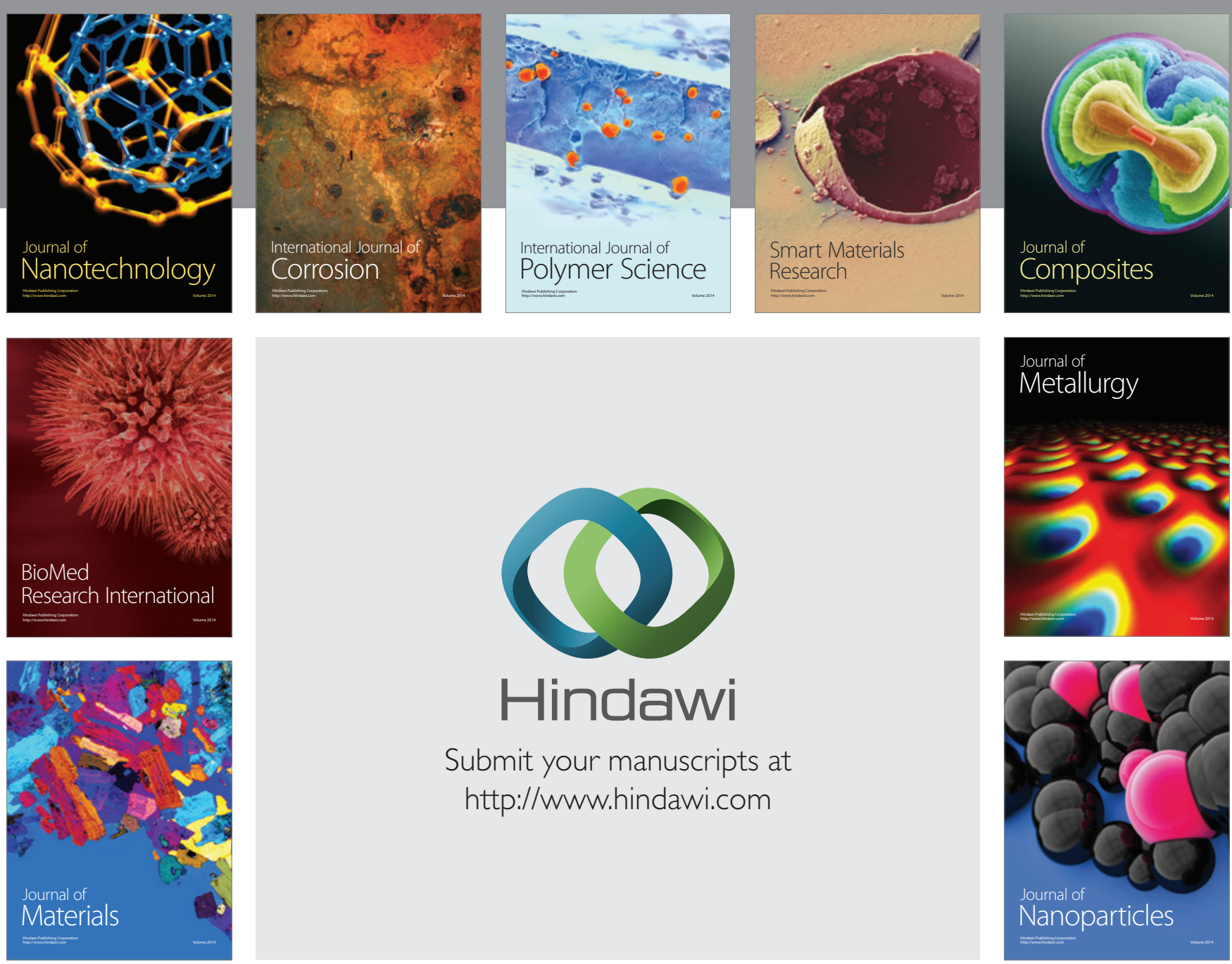

Submit your manuscripts at http://www.hindawi.com
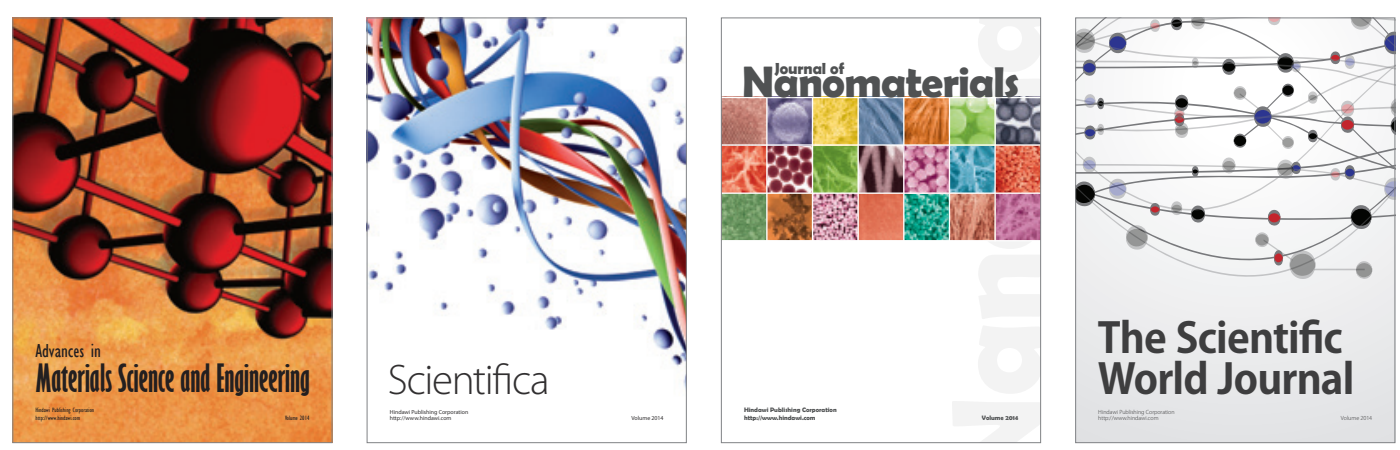

\section{The Scientific World Journal}
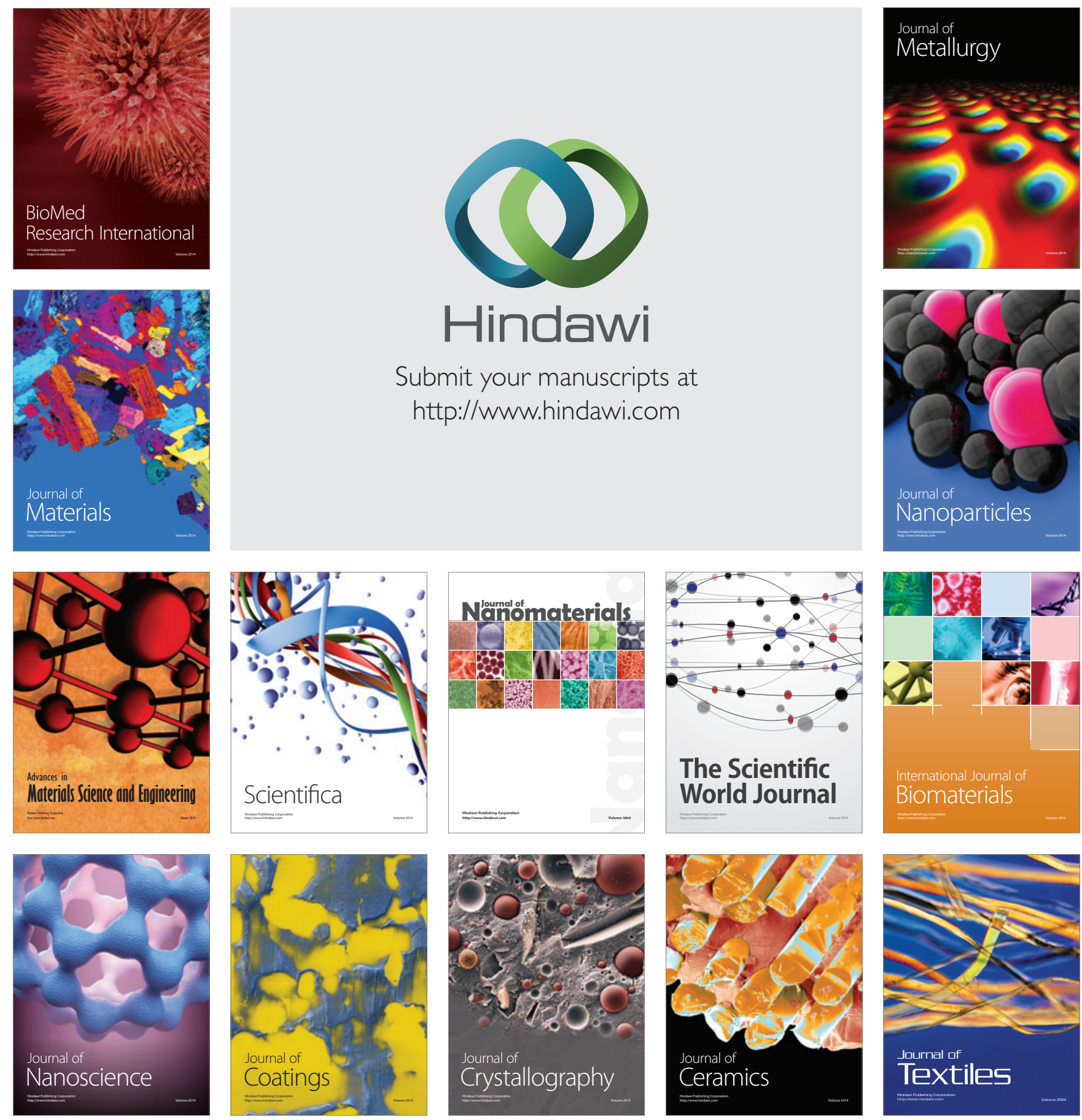